THE INTERNATIONAL

REVIEW OF RESEARCH IN

OPEN AND DISTANCE LEARNING

\title{
Emergent, Self-Directed, and Self-Organized Learning: Literacy, Numeracy, and the iPod Touch
}

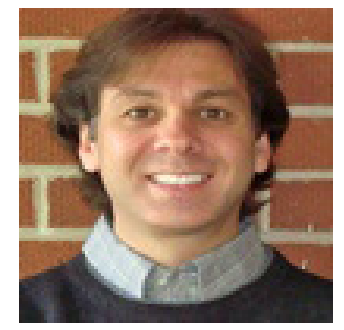

Carlo Ricci

Nipissing University, Canada

\section{Introduction}

This paper uses narrative and storying to retell how two girls ages 5 and 7 continue to make use of an iPod touch to expand their literacy and numeracy. The paper explores the stopwatch and alarm features within the clock application, as well as the weather application, and the Internet browsing capability of the iPod touch. It also explores some of the challenges and inequities inherent in using this type of technology. The paper concludes with the author's belief that it is important to allow learners freedom to explore and freely play with the technology and that emergent, self-directed, and self-organized learning is a natural and gentle approach to lifelong learning.

Becoming literate and numerate is infinitely complicated, yet very simple. It is infinitely complicated because there are so many variables within and without the individual who is learning these skills that understanding the process fully is nearly impossible. Yet, it is simple because so many successfully become literate and numerate so naturally. Relating to this point Schuerwegen (2011) writes,

Ergo, when a child grows up in a reading, writing, counting environment, especially an electronically driven society such as ours, he will one day find the need to pick up all these skills, at least as much as he needs them. (p. 22)

\section{Methodology}

Methodologically this is an autobiographical narrative about technology and literacy and numeracy; specifically, it is about what the introduction of an iPod touch into the lives of two girls ages 5 and 7 has contributed to their ongoing never-ending process of becoming 
literate and numerate. I use the term becoming deliberately because I see literacy and numeracy as a continuum that we are all on. Storying is a powerful qualitative methodology, and I believe that as we share and tell stories we learn a great deal from each other about our world and our lives. Webster and Mertova (2007) write that,

Narrative records human experience through the construction and reconstruction of personal stories; it is well suited to addressing issues of complexity and cultural and human centeredness because of its capacity to record and retell those events that have been of most influence on us. (p. 1)

Clandinin and Connelly (2000) share how "Stories lived and told educate the self and others, including the young and those such as researchers who are new to their communities" (p. xxvi). And Bateson (1994) says, "Our species thinks in metaphors and learns through stories” (p. 11). These visionaries have helped legitimate stories and given me the confidence to share my story. For example, Leggo (2005) reminds us how although much research in education is empirical, we must ruminate on possibilities for research (pp. 443-4). Leggo (2005) writes the following:

A significant part of my ongoing research program is autobiographical remembering and writing about my own experiences of years of study to be a teacher, and years of work as a teacher....I am convinced that by writing about our experiences, and ruminating on those experiences, and interpreting those experiences, we can become more effective teachers, as well as teachers motivated by more joy and hope. (p. 441)

Like Leggo, I am convinced that writing, ruminating, and interpreting our experiences is a legitimate, valuable, and necessary activity. Clandinin and Connelly (2000) add to the legitimating by emphasizing how "Narrative inquiries are always strongly autobiographical” (p. 121). For Clandinin and Connelly (2000), narrative inquiry is stories lived and told (p. 20). Narrative inquiry needs to include argument, description, and narrative (p. 155); however, there is flexibility. They say that, "It is always a matter of experimentation with narrative form" (p. 166). And they go on to say the following:

As we tell our stories as inquirers, it is experience, not narrative, that is the driving impulse. We came to narrative inquiry as a way to study experience. For us, narrative inquiry is the closest we can come to experience. Because experience is our concern, we find ourselves trying to avoid strategies, tactics, rules, and techniques that flow out of theoretical considerations of narrative. Our guiding principle in an inquiry is to focus on experience and to 
follow where it leads. (p.188)

Williams, Karousou, and Gumtau (2008) also used learning narratives, in their case to explore how students actually went about their learning.

\section{Context}

Collins and Halverson (2010) acknowledge that, "even when students are in school, much of their education happens outside" (p. 19). It is clear that learning happens in various contexts. Williams, Karousou, and Mackness (2011) talk about two kinds of learning: prescriptive and emergent. Of prescriptive learning they write,

Prescriptive learning, then, is based on knowledge which is pre-determined for the learners and duplicated and distributed at scale through traditional schools and universities, through print and other mass media, and through national quality-assurance institutions. This covers most formal education in the UK, as well as most traditional publishing and educational broadcasting, and many VLEs [virtual learning environments]. (p. 43)

They define emergent learning as,

learning which arises out of the interaction between a number of people and resources, in which the learners organise and determine both the process and to some extent the learning destinations, both of which are unpredictable. The interaction is in many senses selforganised, but it nevertheless requires some constraint and structure. It may include virtual or physical networks, or both. (p. 41)

Williams, Karousou, and Mackness (2011) go on to say that, "Learning has always included both prescriptive learning (which is fixed and predictable) and emergent learning (which is unpredictable and arises out of the interaction between the learners and their context)" (p. 45). I think that these distinctions are useful for the purposes of this paper. I see prescriptive and emergent forms of learning not as being an either/or, but as constructs that can be approached but never fully reached. What I mean by this is that in the strictest sense there can never be a pure prescriptive nor a pure emergent learning environment. Even in the most fixed and predictable learning environments unexpected learning emerges. Similarly, with emergent learning there are always some things that are fixed and/or predictable. When we talk about these things it may be fair to talk about degrees of prescription and degrees of emergence. I believe this is consistent with the language that Williams, Karousou, and Mackness (2011) use, specifically when they write that, "The interaction is in many senses self-organised, but it nevertheless requires some constraint and structure" (p. 41). 
The language that I have used in the past to describe a degree of emergent learning is learner-centered democratic. The way I use the term learner-centered is not so much in line with the constructivist notion and more in line with an emergent self-organized learning experience. So the learner-centered part refers to situations where learners can self-organize their learning, where they can decide what to learn, where, when, how, and whether to opt in or opt out. And the democratic part refers to a situation where learners have a substantive say in running their lives, whether they are in a school or being home schooled, or in any other context. Mitra (2010) also talks about self-organized learning environments.

\section{The Technology}

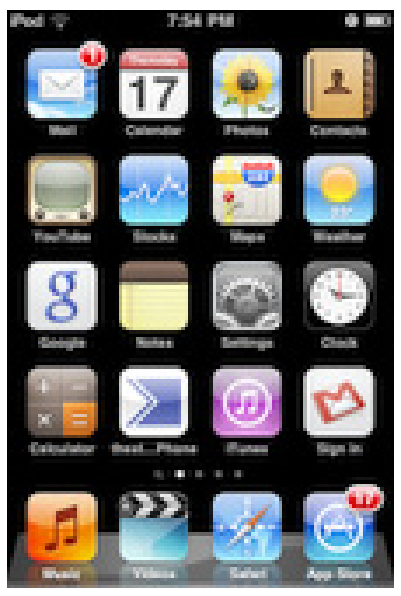

Figure 1. The iPod touch screen.

The iPod touch was first launched on September 5, 2007, and not long after on December 9, 2007, The New York Times published an article by Eisenberg, and this was the first mention of educators using the iPod touch for learning.

In December of 2009 we received an iPod touch. It remained mostly dormant because I did not have the time to sufficiently explore the device's potential; however, in May of 2010 I decided that it was time to explore the potential and power of the iPod touch, and in so many ways I have been and continue to be impressed with its uses. As mentioned, for the purposes of this paper I will share a few examples of how the iPod touch contributed to the ongoing process of becoming literate and numerate in the lives of a 5- and a 7-year old girl.

At this point our iPod touch has very few applications downloaded onto it and is essentially restored to the factory settings. I will describe how the iPod touch was embraced and enjoyed by the girls and how in the process of manipulating and playing with the device, impressive opportunities for learning literacy and numeracy were observed by me. The most interesting part in all of this is that the girls strengthened their literacy and numeracy skills incidentally. What I mean by this is that we did not purposefully seek the device as a learning tool, but merely stumbled across it and are now using it because it is what we want to do, and as a result learning is happening. This is in line with Holt's (1989) definition of edu- 
cation where he writes, "Living is learning. It is impossible to be alive and conscious (and some would say unconscious) without constantly learning things" (p. 157).

This natural learning is not unique to the iPod touch but is evident in all forms of technology from a cereal box, to a television, to a television remote, to a laptop. Literacy and numeracy and learning constantly happen, sometimes when we least expect it. So, in what follows I will describe only a few of the basic applications that were preloaded on the iPod touch, and I will share what creative and imaginative uses the two young girls made of it and how those activities extended their literacy and numeracy.

\section{Stopwatch}
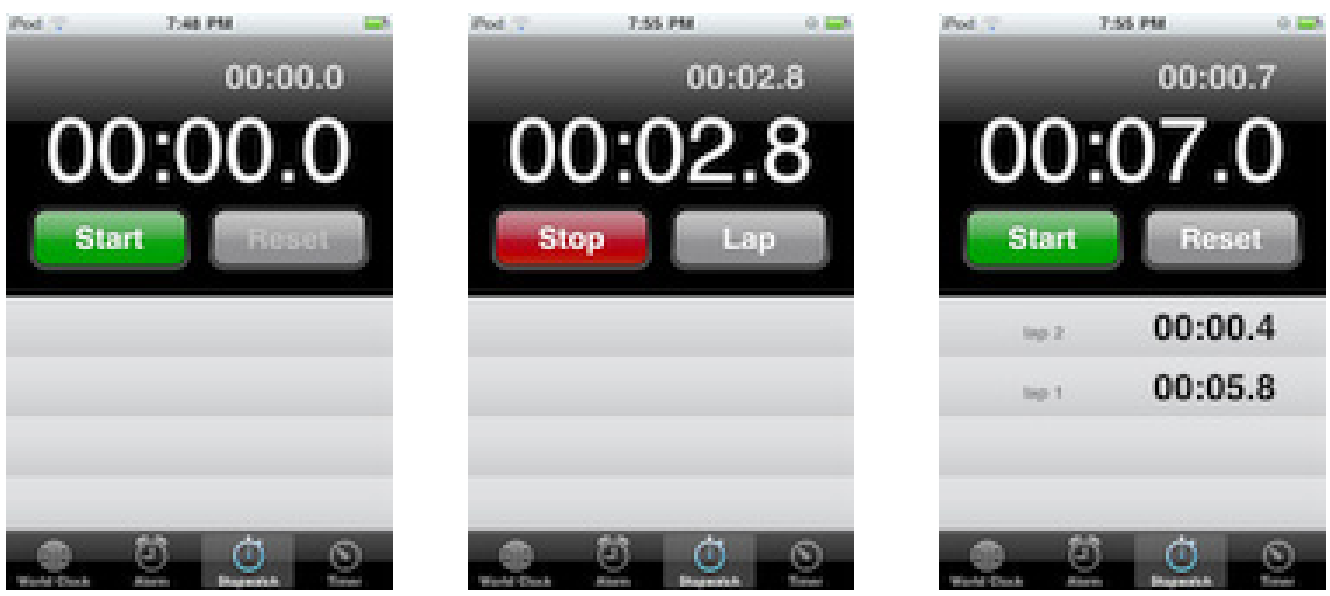

Figure 2. The stopwatch application.

The first application that the girls explored and that I want to share with you is the clock application; specifically, the stopwatch feature and the timer that is within the clock application. First, the stopwatch. The younger girl started running along a fairly long, narrow hallway on the second floor of a two-storey home. The total distance from one side to the other is approximately 50 feet. While they were doing this, I mentioned to them that the iPod touch has a stopwatch feature and if they liked we could use it to time how long it took them to run back and forth. They enthusiastically agreed. I mentioned to them that they had to tap the green start button to start. Once the start button is tapped it turns red and then reads stop, and so they needed to tap stop in order to stop the clock, and then they could read their time that is recorded on the screen.

I then noticed that once start is tapped there is a button next to it that reads reset and it turns into lap. I mentioned it to them and we decided to explore how that feature worked. The first time around, the younger decided that she would run three laps and the older would work the stopwatch; they then switched. This was a great learning experience for all of us and the contribution to our ongoing literacy and numeracy was inspiring. In sum, the girls would run their laps and the stopwatch recorded their overall time and below that it recorded their time for each lap. We were able to see if they ran each lap faster or slower or 
the same.

By playing with and exploring the iPod touch many mathematical and language concepts naturally increased our understanding of literacy and numeracy regardless of whether we were consciously aware of it or not. Again, the object of our engagement was not to strengthen our literacy and numeracy skills, yet that is clearly what resulted. What the girls learned is beyond my imagination and so I cannot define it definitively, but they were using language like, "you ran it in 9.2 seconds." The use of decimals in this way is something I had not heard them use before.

This is a clear example of emergent learning as defined above by Williams, Karousou, and Mackness (2011). This is the case with the other applications that were explored on the iPod and that are referred to later on in this paper. I will spend some time here making the specific connection and then trust that the reader can transfer what is said here and apply it to the other examples because the connections are similar.

Specifically, the connection between emergent learning in this case is, first, that the learning arises out of the interaction between a number of people and resources. In our case the people were the two young girls and I, and the resources are included within the iPod; in this case it was the stopwatch feature which is a part of the clock application. Second, as participants we organized and determined both the process and to some extent the destination, both of which are unpredictable. In our case we decided that we wanted to time the girls as they ran laps. The learning that happened was clearly unpredictable because, in truth, we did not set this out as a specific learning activity, but the result was that learning happened. In other words we did not have any learning goals in mind before we started the activity, there was no prescribed curriculum, but by the end of it we could certainly share many things that we learned for having participated in the activity.

Third, the interaction was self-organized, yet there was constraint and structure. We decided the rules, and although they were fluid, we did have constraints and a structure. As we went along and discovered new things we made changes to the activity and so in this sense it was fluid. For example, we incorporated the lap feature. We clearly had our imposed constraints and structure, as well as the ones inherent within the resource we used. Finally, emergent learning includes virtual or physical networks or both. In our case, the networks were physical because we were in the same place.

I see this definition of emergent learning as being a useful guide, but not a closed recipe. For example, when Williams, Karousou, and Mackness (2011, March) write of emergent learning as, in part, "learning which arises out of the interaction between a number of people and resources," I can think of situations where learning can happen with a contemplative person and her thoughts or her self as the resources. Having said that, I agree that the definition provided is a very useful starting point to begin a conversation around what it means for learning to emerge. What resonated most with me is the need to self-organize and the understanding that the learning is not prescriptive, but unpredictable, emergent. 


\section{Alarm}

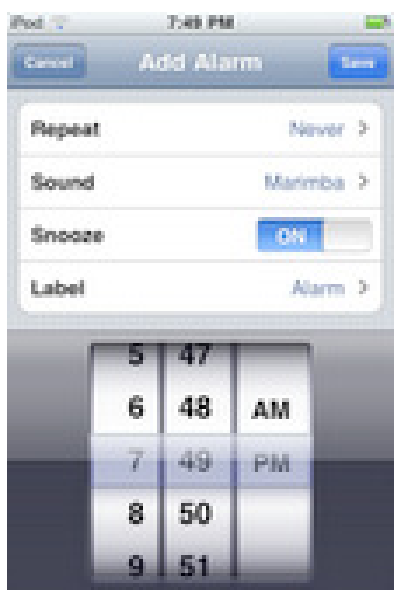

Figure 3. The alarm screen.

Second, connected with the clock application is an alarm. The girls wanted to hear it ring and so they suggested we set the timer to one minute. They realized that that was the smallest option and did not want to wait an hour, for example, to hear the sound. They counted down along with the iPod and cheered when the number hit zero and the tone of the Marimba was heard. Quickly, they became a little disappointed at the sound and were excited when they realized that they could change the sound. The process was repeated for different sounds and they settled on the bell tower. Again, this application resulted in extending their use of literacy and numeracy.

\section{Weather}
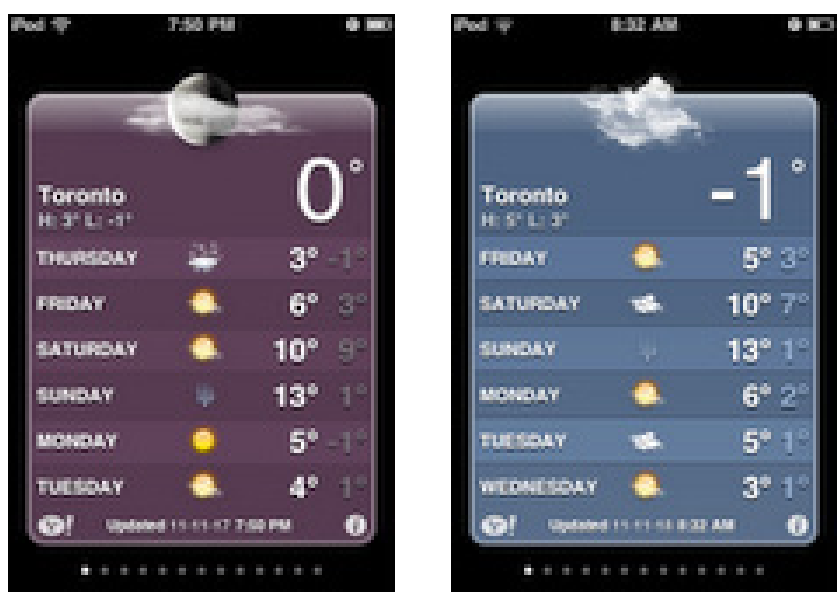

Figure 4. The weather application.

Third, there is a weather application. The girls are very interested in what the weather will be like and in the past have used the television (there is a station that has the weather displayed for the day and forecasted for another four days in advance) and the weather feature 
located on my laptop, so they are familiar with the weather feature. This did not limit their enthusiasm when they discovered that they could check the weather using the iPod touch. One advantage of the iPod touch over the other two mediums I mentioned is that on the iPod touch the whole word for the day is spelled out. So, for example, Friday is not shortened to Fri., but is spelled out. Again, this will, I believe, help with their literacy. I have to say that they are already well on their way to reading and the older girl is already reading short novels, while the younger is building her vocabulary and understanding of how letters work to form words and is moving along very swiftly. Nevertheless, as I mentioned earlier, I see literacy and numeracy as being on a continuum, and so we do not just become literate and numerate in one day, but we move along the continuum of literacy and numeracy and the iPod touch clearly extends skills in powerful ways along this journey.

With the weather application the girls learn to connect numbers to what they have to wear based on how hot or cold it is outside. As well, looking up the weather has introduced them to negative numbers and they are able to use them fairly skillfully. In part, the weather application has helped them learn the days of the week, the months (which they also learned about because of birthdays and other significant events that we talk about in advance and that they look forward to), and the year. The calendar application on the iPod touch has clearly helped with them learning these skills, but I will not go into detail about that except to say that they wanted to write their birthday, for example, within the calendar using the touchpad. The weather application also helps them understand daily highs and lows because they are clearly listed, along with the symbols used to indicate whether the day will be sunny, cloudy, and so on. 


\section{YouTube}

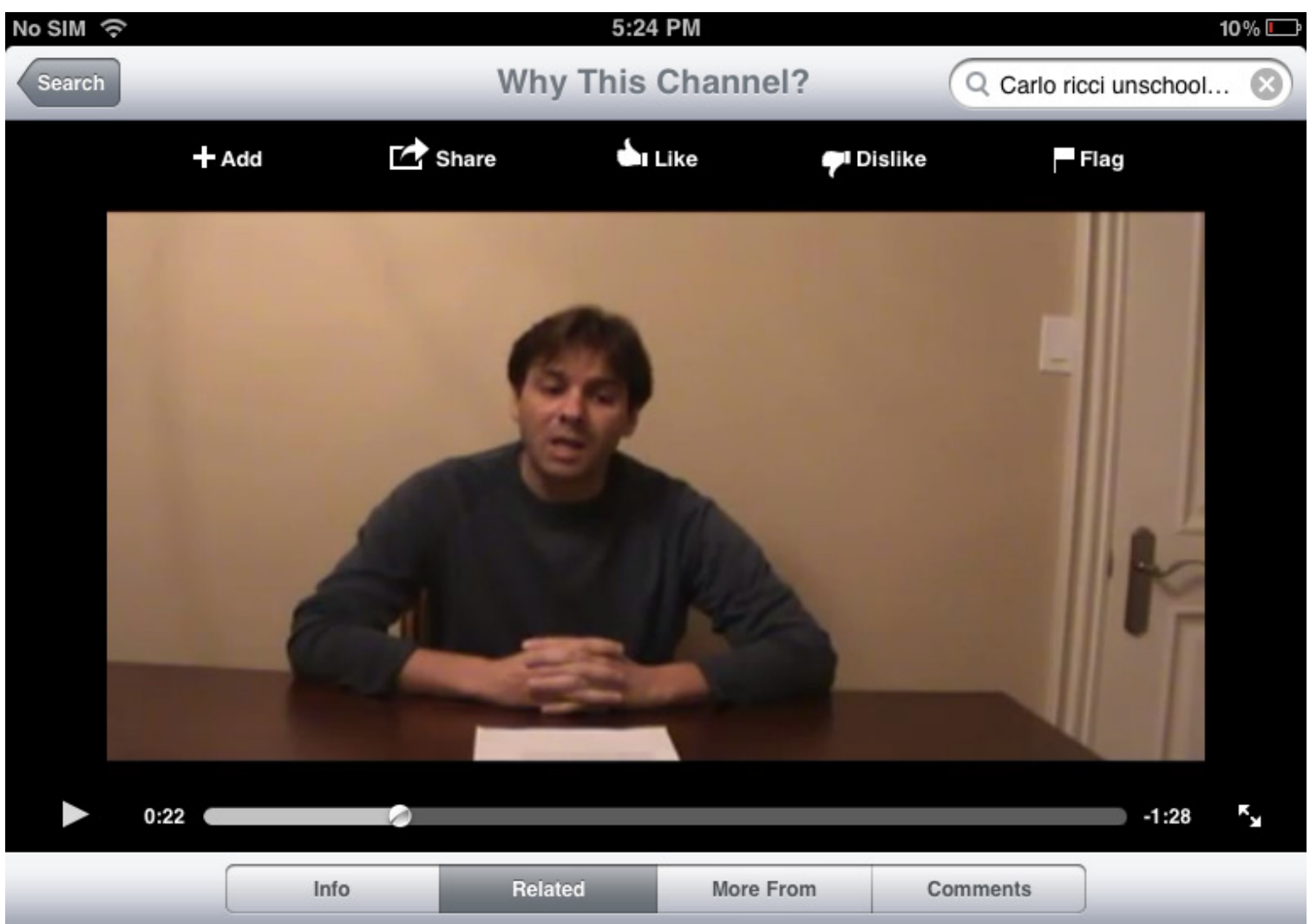

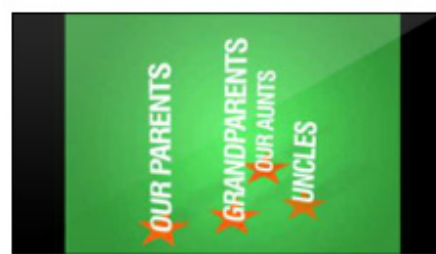

Alternative education ... 462 views yic6b

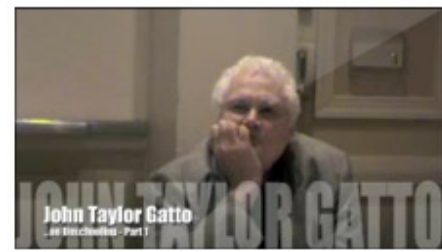

John Taylor Gatto on Unschooling - Part 1 6,154 views UnschoolingChannel

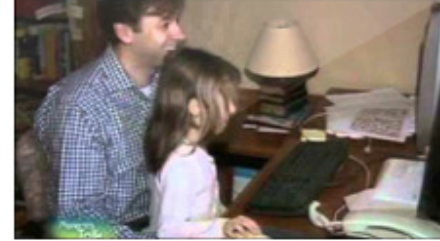

Carlo Ricci on Parents Talk 03:24

1,156 views

UnschoolingChannel @100\%

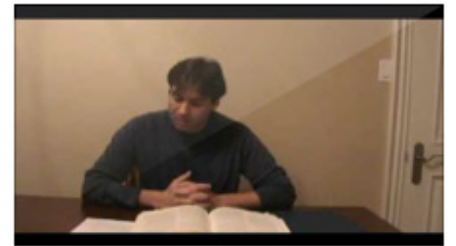

Dewey Versus Holt

765 views

UnschoolingChannel

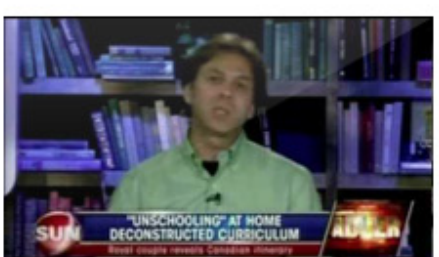

Carlo Ricci on Sun TV

$07: 40$

1,054 views

UnschoolingChannel @100\%

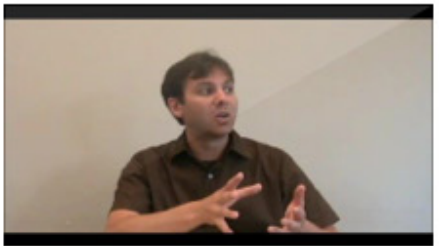

Unschooling and Getting $01: 36$ into Post Secondary Educ...

1,192 views

UnschoolingChannel

Featured

Figure 5. YouTube screen. 
Fourth, the iPod touch has an application for YouTube. The girls wanted to hear songs from their current favorite artists and they needed to learn to spell the artists' names in the search field so that they could access the video they wanted. For this they knew how to spell Justin but were not sure about Bieber, and they went to get their compact disk so that they could spell it correctly; similarly, for the spelling of Montana, they went to get their Hannah Montana CD. While they are watching and listening to the video there is a continuum that displays how much of the video has been played on one side and how long the video is on the other, further enhancing their literacy and numeracy skills.

\section{Discussion and Conclusion}

Two questions remain: First, how sustainable will their interest in using the iPod touch be? And, second, how will it continue to increase their literacy and numeracy skills? One very serious issue for me is the financial cost to this type of technology, and related to this is the issue of accessibility. This technology is not cheap and it is constantly changing. The iPod touch is $\$ 199$ for $8 \mathrm{~GB}$ (also offered is $32 \mathrm{~GB}$ for $\$ 300$ and $64 \mathrm{~GB}$ for $\$ 400$ ); in addition, my monthly high speed Internet charge is about $\$ 500$ a year. As well, the wireless system I put in to maximize use of the technology we have also comes at a cost. My wireless router cost $\$ 200$ and I also had to purchase an extender for $\$ 79.99$ so that I can boost the signal and extend the use of my wireless in a room that is a dead zone, but that we spend a fair bit of time in. Ideally, I would like to have the 64GB iPod touch and its enhanced features over the one I have, but cost is a factor. Even more wishful, I would like to have the iPhone with a data package to truly take advantage of mobile learning, where as Bonk (2009) writes, "Anyone can now learn anything from anyone at anytime" (p. 7). Again, cost is a factor. Collins and Halverson (2009) write about the digital divide, "the difference in access to computers and the web between rich and poor, and white and non-white people" (p. 106).

In conclusion, I hope my story helps others appreciate the fact that technology can enhance the learning of literacy and numeracy in very natural and powerful ways. Of course, in interacting with the technology, the girls also learned a great deal about technology itself. As I put the finishing touches on this piece my younger daughter came up to get the iPod touch and bring it downstairs so that she could "look at stuff." Awhile earlier she checked her email on it and sent out a few messages: one to her mom and another to her aunt. They also use the Safari web browser which again extends their learning.

The iPod touch has numerous other applications that can be downloaded, some for a fee and some for free. I look forward to continuing my exploration and observation around this powerful technology for not only literacy and numeracy, but learning of all kinds. Of the iPhone, Bonk (2009) writes that it "is yet another device that will add steroids to human mobility. You can check email, text message friends, browse, collect, and share information and pictures online, and handle phone calls" (p. 299). He goes on to say that through applications, smart phones "include things like quick guides for chemistry, the human nervous system, cell biology, and other important science areas as well as religious topics ranging from the Qur'an to the Bible to the gods of ancient Greece" (p. 299). He says that the 
"iPhone and other smartphones represent a portable learning device that is a key driver for the current learning revolution" (p. 299). Given that the iPod touch is similar to the iPhone, albeit much less powerful, I believe that similar things can be said of it. Finally, and most importantly, I believe, is that we need to allow learners to freely play with the technology so that they can engage with and stumble on skills naturally and as they see fit. This is not to say that an external person cannot offer support, but that the learner needs to have a voice and she needs to be empowered to make substantive decisions and choices. 


\section{References}

Bonk, J. (2009). The world is open: How web technology is revolutionizing education. San Francisco: CA: Jossey-Bass.

Collins, A., \& Halverson, R. (2009). Rethinking education in the age of technology: The digital revolution and schooling in America. New York, NY: Teachers College Press.

Collins A., \& Halverson R. (2010). The second educational revolution: Rethinking education in the age of technology. Journal of Computer Assisted Learning, 26, 18-27.

Eisenberg, A. (2007, December 9). What did the professor say? Check your ipod. The New York Times, p. B2.

Holt, J. (1989). Learning all the time: How small children begin to read, write, count, and investigate the world, without being taught. Cambridge, MA: Da Capo Press.

Mitra, S. (2010). The child-driven education. TED presentation. Retrieved from http:// www.ted.com/talks/lang/eng/sugata mitra the child driven education.html

Schuerwegen, L. (2011, November/December). The sky is blue. Or is it? The essential knowledge debate: Are there subjects that must be learned? Life Learning, 20-22.

Webster, L. \& Mertova, P. (2007). Using narrative inquiry as a research method: An introduction to using critical event narrative analysis in research and teaching. New York, NY: Routledge.

Williams, R.T., Karousou, R., \& Gumtau, S. (2008). Affordances for learning and research (Final project report for the Higher Education Academy). Retrieved from http:// learning-affordances.wikispaces.com/Project+Report

Williams, Karousou, \& Mackness. (2011). Emergent learning and learning ecologies in Web 2.0. International Review of Research in Open and Distance Learning, 12(3), 39-9.

\section{Athabasca University $\mathbf{A}$}

